\title{
ETHICAL DILEMMAS AND MORAL MUTENESS IN THE HRM PROFESSION
}

\author{
SÁRA CSILLAG \\ Institute of Management, Budapest Business School, Hungary \\ Email: csillag.sara@uni-bge.hu
}

\begin{abstract}
What does ethics mean in human resource management (HRM)? In this paper, based on the results of action research projects conducted with the participation of $76 \mathrm{HR}$ experts in five groups, we provide insights into two issues. First we identify the most common dilemma-patterns in HRM activities in present-day Hungary (dismissal, disciplinary actions, recruitment and organizational culture). Then, we move on to the reasons for moral silence as identified by HRM experts (among others, a lack of ethical knowledge, the lifelessness of the ethical institutional framework, ignorance and fear, power games and buck-passing).
\end{abstract}

Keywords: human resource management, ethic, moral muteness

JEL-code: M54

\section{INTRODUCTION}

More and more business, political and academic forums stress the importance of sustainable, responsible and ethical corporate operations. Yet one may ask what does this mean - if anything - in everyday practice? What kind of problems do employees have to tackle or what are the most characteristic ethical issues in a given area? In this paper, we focus on human resource management (HRM), which is perhaps one of the most challenging, exciting and controversial professional areas from an ethical point of view. HRM professionals not only face ethical dilemmas everyday connected to (among others) selection, disciplinary procedures or compensation decisions, but could have serious impact on the ethical or unethical 'nature' of the corporate culture as well (Greenwood 2013). 
Among the several interesting questions connected to HRM ethics, in this paper we address two issues: (1) Which HRM system accumulates the most ethical problems (and within this, what are the most characteristic patterns?); and (2) How does the principle of moral muteness appear in the practice of HR managers?

As HRM professionals are key players, in order to investigate the questions we grouped and analysed the real-life cases collected by 76 professionals (revealing that dismissal, disciplinary actions, recruitment and organizational culture are the most frequent issues), and used their research diaries to identify the most relevant patterns of moral muteness (among others, a lack of ethical knowledge, the lifelessness of the ethical institutional framework, ignorance and fear, power games and buck-passing).

The structure of the paper is the following: first, the paper gives an overview of the theoretical background of HRM ethics and the patterns of moral muteness. Next, the article discusses the methodology used and the practical details of the process. Then the main results of the research are presented. The paper closes with a conclusion providing arguments for the points of contributions mentioned above, along with the limitations and future research directions.

\section{THEORETICAL BACKGROUND}

'Ethics' refers to proper conduct and HRM, in essence, means dealing with and caring for people: one may think that the two are organically interrelated. Although discourse on employee rights has long been present in the literature of business ethics, the relationship between ethics and HRM is not as advanced, and less studied (Greenwood 2013). While in the past 25 years there has been a growing interest in this field, as seen in articles (Dachler - Enderle 1989; Winstanley - Woodall 2000; Csillag 2013; Guersi et al. 2015; Linehan - O’Brien 2017; Nasir 2017), edited volumes (Deckop et al. 2006; Bolton - Houlihan 2007), and appearances in more and more HRM textbooks (De Cieri - Kramar 2005), empirical research is still insufficient (Pinnington et al. 2007).

The theoretical and practical study of HRM is connected to the diversity and complexity of the concept of ethics itself. Considering ethical frameworks, Goodpaster (2007) differentiates among interest-based, rights-based, duty-based and virtue-based ethical trends which Schumann (2001) - with special regard to HRM analyses - complements with the theory of distributive justice and the ethics of care. Greenwood (2013) offers a new, pluralistic ethical paradigm (surpassing mainstream HRM with a critical edge to HRM elements) for the studying of ethical issues. It is important to decide if we should apply a particular framework in empirical study and consider the reasons for that choice. 
Martin and Woldring (2001) claim that HRM ethical aspects and issues may be interpreted on several interwoven levels: the macro (social and economic system); mezzo (corporation and HRM levels); and micro (individual) level. At the macro level, for example, ethical criteria may be set against the different capitalist models or the basic principles and operations of the modern-day corporation (Legge 1995). At the mezzo level, an important aspect may be the current changes in HRM, the spreading and ethicality of the business partner model (with the related centralizing and outsourcing operations), or which ethical aspects (e.g. equal treatment) and to what extent are considered in the forming and running of HRM systems. Finally, personal or professional ethical dilemmas affect the individual HRM professional as well, as seen in the dilemma of dual membership, i.e. the conflicts and contradictions between organizational and professional membership (Ekuma - Akobo 2015). These levels are interconnected - making empirical research more difficult.

Although low in number, the theoretical or empirical studies focusing specifically on HRM experts and their struggles with ethical issues may be put into four groups. Some authors typify characteristic ethical dilemmas (see Table 1 for details), highlighting the most common or most difficult cases. Others gather dilemmas and issues related to a specific HRM system (Longenecker - Ludwig 1990; Jacobs et al. 2014) or focus on a range of problems, e.g. the effects of outsourcing (Park - Hollinshead 2011). The third group of studies deals with problems related to a given basic principle, such as justice or fairness (Pichler et al. 2016; Sung et al. 2017). Another group deals with ethical contradictions, conflicts, and phenomena related to the role of HRM representation (Orlitzky - Swanson 2006; De Cremer 2009).

Ekuma and Akobo (2015) emphasize the importance of exploring and understanding the patterns of practical cases, as does this empirical and exploratory study.

In conclusion, we must ask what is it that restrains employees in general (including HRM experts) from talking openly about ethical dilemmas and solving problematic cases. According to the theory of Bird and Waters (1995), one reason may be the phenomenon of moral muteness. Employees face (manifold) normative expectations at their workplace. These important behavioural standards may come from several sources, e.g. national culture, regulatory frameworks, professional codes, corporate policies, etc., and influence the individual's conduct at the workplace as well. Verbal communication plays a very important role not only in the setting, identification and transferring of normative expectations, but also in the evaluation of behaviour or in the encouragement given to meet expectations. According to Waters et al. (1987), moral muteness is a situation when individuals avoid talking about moral issues although they possess firm ethical principles, 
Table 1. Authors gathering ethical problems, cases and topics

\begin{tabular}{l|l}
\hline Authors & \multicolumn{1}{c}{ Ethical problems, cases, topics } \\
\hline $\begin{array}{l}\text { Fusilier et al. } \\
1996\end{array}$ & $\begin{array}{l}\text { Work safety, employee thefts, improper protection of data, discrimination, } \\
\text { unfair compensation. }\end{array}$ \\
\hline $\begin{array}{l}\text { Mathis - Jackson } \\
\text { Infor }\end{array}$ & $\begin{array}{l}\text { Information processing and retention, the collection of data, personal rights } \\
\text { in cases of AIDS and other diseases, the prohibition of smoking, treatment } \\
\text { of long-time employees with permanent health problems. }\end{array}$ \\
\hline Weiss 1997 & $\begin{array}{l}\text { Favour-based selection and promotion, discrimination on the basis of sex, } \\
\text { age or nationality, consistency in disciplinary cases performance-evaluation, } \\
\text { bribery, improper protection of data. }\end{array}$ \\
\hline Gantz - Hayes & $\begin{array}{l}\text { The use of psychological tests, the underplaying of trade unions, dismissal } \\
\text { decisions, the setting up of non-transparent job duties, consistency in } \\
\text { disciplinary cases, wage bargain. }\end{array}$ \\
\hline Wiley 1998 & $\begin{array}{l}\text { Favour-based selection, promotion, harassment, inconsistent disciplinary } \\
\text { procedures, evaluation, discriminative practices. }\end{array}$ \\
\hline Ryan 2006 & $\begin{array}{l}\text { Manifest and latent discriminative selection, favoritism and incongruence in } \\
\text { selection and performance evaluation. }\end{array}$ \\
\hline
\end{tabular}

Source: compiled by the author.

perceive and react to moral expectations, and in certain cases they even follow their principles in practice. McCoy (1989) argues that even though leaders make decisions in accordance with their own values they hide their real motives behind a veil of economic interest.

Research carried out by Bird and Waters (2005) suggests that individuals and communities can be 'morally mute' because of four main factors. (1) Fear of losing harmony and a sense of loyalty: in many cases, they think that raising ethical issues may pose a threat to the harmony of the organization and generate destructive conflicts, which will then be difficult to settle. Although they perceive ethically questionable practices and are aware of certain discriminative moves for promotion, they believe that raising ethical issues in public will do more harm than good. (2) Fear of losing efficiency: people think that talking about moral issues is a waste of time which makes efficient decision making harder and slower: it often leads to scapegoating and creating ideologies. They see it as the manifestation of inflexibility, the infringement of certain liberties and the increase of red tape (Drumwright - Murphy 2004). (3) Fear of losing power: some leaders feel that a discourse on moral issues may threaten their power and perceived efficiency: in certain cases they are less well-informed and tend to be ignorant of the relevant moral arguments and usage of specific terms, which would be hard to admit. The chances of moral muteness are further increased by the notion that moral arguments are more often than not utopistic, removed from real life and discussing them will only ruin the image of power and prestige (Bird 2005). 
(4) Passing responsibility: individuals think that they are just small cogwheels in a big machine and it is not their job to change things they know are wrong. Lovell (2003) identifies another group as (5) cynicism: employees maintain that the immorality and cowardliness of the surrounding community make it pointless to follow any kind of ethical discourse. Similarly, Verhezen (2010) talks about the 'culture of silence' when individuals do not have the proper means of articulation or feel awkward when they have to speak about ethical issues. The counterpoint of moral muteness is the stressing of moral arguments and moral conversations (Brinkmann et al. 2016), and taking morally grounded action. But how can one support individuals as a means to move in this direction? Lowell (2003) says that the greatest hindrance and at the same time the greatest support may be provided by the organizational or professional environment: in our case, the professional community of HRM experts.

\section{RESEARCH PROCESS}

As mentioned before, the number of empirical studies on HRM ethical issues is limited in the literature, although several scholars emphasized the importance of more research (Greenwood 2013; Ekuma - Akobo 2015). The scarcity of empirical evidence is even more revealing if we search for studies focussing on the Hungarian context (Csillag 2013). In order to contribute to filling this gap, our present paper aims to explore two questions: (1) Which HRM system accumulates the most ethical problems (and within this, what are the most characteristic patterns?); and (2) How does the principle of moral muteness appear?

To find answers to the questions, we analysed ethical cases gathered by 5 different expert groups, complemented by the participants' research and reflection diaries. Between 2013 and 2017, a total of 76 experts took part in the HRM ethics course and mini-action-research organized by the HR business partner postgraduate program at the Corvinus University of Budapest. Each group met at least four times. On the first occasion, the focus and questions of the research were decided together, individual and team actions (e.g. making interviews, leading focus groups, viewing and analysis of films, etc.) were planned. Between personal meetings (and sometimes at the meetings) actions were carried out followed by shared reflections, and the next steps of the research were decided. A research and reflection diary was written during and at the conclusion of the course. In this paper we do not analyse the action-research process or focus on the shared interpretations of the participants, but analyse the patterns of cases identified and the nature of moral muteness revealed. 
The age of participants was between 30 and $57,88 \%$ of them were female (reflecting the high proportion of female HR experts in Hungary). At the time of the course, nearly $70 \%$ of them worked as HR leaders or business partners (both positions have a very mixed content in Hungary today - this is how they defined themselves). The 8 participants in non-HR positions were leaders, partners or experts (generalist or specialist), a mother at home on maternity leave, and corporate experts who had plans or had already made decisions concerning switching to HRM. Those who worked in HR areas were all employed by large companies including a mix of multinational, state-owned and Hungarian-owned companies, practically representing all industries and sectors.

The answer to the first research question was given by cases gathered by participants. The five groups came up with a total of 149 specific, personally experienced cases with ethical implications. During the courses the participants gathered personally experienced and concrete cases in the past or present (i.e. excluded theoretical dilemmas, or indirectly related stories), which happened to them or in their immediate environment and which were written down by themselves.

We decided to code the gathered cases according to how they best relate to a given HRM system. Here, we made some arbitrary subdivision of HRM systems (e.g. flow was subdivided into four items) and we finally set up 14 groups (see Table 2). In some cases, there were more than one option but we decided where it would fit better so that each case was put into only one group. We used NVivo softwere for the coding process.

The answer to the second research question is partly based on the cases and on the participants' research and reflection diaries. The diaries of the participants produced a total of 550 pages which we encoded with the help of NVivo again: we used the patterns of moral muteness identified in the literature as starting codes. In the analysis of results we decided to use word-for-word quotations, which we modified only in order to protect the identity of the companies and the professionals. For further protection, we decided to use the quotations without identification codes, and we asked the permission of the participants to publish the quotations.

\section{RESULTS - PATTERNS OF ETHICAL CASES}

Not surprisingly, most of the cases are related to dismissal and disciplinary cases (36), recruitment and selection (28) and organizational culture (22). These three topics will be covered in detail and Table 2 shows the HRM systems, the number of related cases and their rate compared to the total number of cases. 
Table 2. Division of cases

\begin{tabular}{l|c|c}
\hline HR system & Number of cases & Share of total \\
\hline Recruitment-selection & 28 & $19 \%$ \\
\hline Career management & 5 & $3 \%$ \\
\hline Employment relations & 2 & $1 \%$ \\
\hline Compensation & 15 & $10 \%$ \\
\hline Health and work safety & 22 & $9 \%$ \\
\hline Organizational culture & 0 & $15 \%$ \\
\hline Planning & 4 & $0 \%$ \\
\hline Performance evaluation & 36 & $3 \%$ \\
\hline Dismissal and disciplinary cases & 2 & $24 \%$ \\
\hline Promotion & 6 & $4 \%$ \\
\hline Reintegration & 7 & $5 \%$ \\
\hline HRD & 8 & $5 \%$ \\
\hline Administration, data processing & 1 & $1 \%$ \\
\hline Work systems & 149 & \\
\hline
\end{tabular}

Source: author.

\subsection{Dismissal and disciplinary cases}

This issue involved 36 directly related cases with the following foci:

For many cases, problems appear in the dismissal process, such as the perception of unlawfulness, irregularities, unpreparedness, inhumanity, and cruelty, the attitude and behaviour of the leader (e.g. accusation, shouting or the absence of the leader) or doubts about the bargaining of the dismissal package.

With a certain overlap, but also as an independent element, the problems related to the criteria of dismissal decisions surfaced as well, e.g. distorted and unfair aspects in the selection of a person to be dismissed (especially when the person to be dismissed is named 'from above'), also conflicts involving performance/indigence or performance/attitude.

The above-mentioned topics relate to the third issue of the road leading to dismissal: in many cases, the reasons for dismissal include random organizational changes and transfers, deficiency in management and the lack of feedback.

Dismissal is usually entwined with all kinds of communication problems: not only with the dismissed person before, during and after the process but also with the rest of the organization. Also, some questions surfaced connected to what the HR manager can (should) do with the information and knowledge gained from an exit interview.

Another division relates to disciplinary offenses. HR managers struggle with considerable problems with definitions and regulations both concerning the 
offenses themselves, and the areas of controlling and sanctioning. Characteristic issues include the use and misuse of the internet, political engagement and exposure outside the workplace, physical atrocity, alcohol abuse and mobbing.

Closely related are the issues concerning the process of handling disciplinary cases: although the fact of the offense is obvious, the procedure is not clearly regulated. The whole process is conducted in an unprofessional or even discriminative way, not all parties are given a fair hearing, the verdict is determined beforehand or, in many cases, the attitude and behaviour of the employee (or the leader) is also problematic.

The above-mentioned groups may also include overstated charges in disciplinary cases or dismissals 'ordered from above'. In several cases, the HR manager was supposed to create a pretext or assist with dismissals ordered by higher management. Following the wish of senior management to 'create a precedent', HR managers were required to exaggerate minor or even unprovable disciplinary offenses. In striking contrast, serious offenses committed by high-performaning employees were covered up.

Table 3. Patterns related to dismissal, with relevant cases or excerpt from a case

\begin{tabular}{l|l}
\hline Foci & \multicolumn{1}{c}{ Characteristic case or excerpt from a case } \\
\hline \multirow{5}{*}{ Dismissal process } & $\begin{array}{l}\text { "One of our managers received complaints about a colleague several } \\
\text { times. Some people said he was unable to cooperate. The manager } \\
\text { talked to the colleague on many occasions, but he wouldn't change } \\
\text { his behaviour. On the last of such an occasion, the manager fired him } \\
\text { with immediate effect, on the spur of the moment, without consult- } \\
\text { ing HR. All he told us was the fact of his final decision, but we still } \\
\text { tried to convince him by saying we were not sure it was a legitimate } \\
\text { thing to do. Also, we hadn't considered such ethical issues as the } \\
\text { colleague's 12-year-long loyalty, great professional skills, and other } \\
\text { merits." }\end{array}$ \\
\hline $\begin{array}{l}\text { "Downsizing - as an economic precaution. I have to dismiss one } \\
\text { of two people. From a strategic point of view, neither of them is a } \\
\text { decisions }\end{array}$ & $\begin{array}{l}\text { key figure, but both of them have been with the company for over } \\
5 \text { years with similarly mediocre performance. One of them (a man) } \\
\text { definitely irritates me but has two primary school children and loads } \\
\text { of mates in the company. The other 'candidate', a single woman, } \\
\text { probably has lower chances of finding another job." }\end{array}$ \\
\hline $\begin{array}{l}\text { Problems on the road } \\
\text { to dismissal }\end{array}$ & $\begin{array}{l}\text { pain character: a department chief at a large multinational com- } \\
\text { performance. Then, the team split up and he got a Czech team, but } \\
\text { he doesn't speak Czech, so neither the clients nor the colleagues ac- } \\
\text { cepted him really. He asked for help from his immediate superior and } \\
\text { the area manager as well. He spoke to HR several times. Instead of } \\
\text { getting help, he was dismissed." }\end{array}$ \\
\hline
\end{tabular}


Table 3. continued

\begin{tabular}{l|l}
\hline Foci & \multicolumn{1}{c}{ Characteristic case or excerpt from a case } \\
\hline & $\begin{array}{l}\text { "This is the practice: we walk with him to his computer and wait } \\
\text { until he downloads any personal content, packs his things and we } \\
\text { walk him out. I've been in this role many times and I must admit it's } \\
\text { a really hard and unrewarding task. This situation hit rock bottom } \\
\text { last year when several employees were dismissed. Not as a group } \\
\text { but over a period of time. It was mostly due to economic reasons; } \\
\text { the process could not be done at the same time so the employees } \\
\text { came to work in fear. It was not just about their own position. It was } \\
\text { a rather distressing thing, spiritually, to find all of a sudden the desk } \\
\text { of a teammate cleared off." }\end{array}$ \\
$\begin{array}{l}\text { surrounding dismissal } \\
\text { Problems with } \\
\text { definitions and } \\
\text { regulations concerning } \\
\text { disciplinary action }\end{array}$ & $\begin{array}{l}\text { "Can I challenge employees for using too much internet? But what } \\
\text { is too much? 1 hour? 2 hours? And what if he or she works harder in } \\
\text { the remaining 6 hours than another colleague in 8 hours? How can } \\
\text { I save face if I do not sanction other 'tricksters'?" }\end{array}$ \\
$\begin{array}{l}\text { The process of handling } \\
\text { disciplinary offenses }\end{array}$ & $\begin{array}{l}\text { "I was working for a multinational firm when a very derogatory } \\
\text { rhyme and a video was uploaded to Youtube. Based on the upload } \\
\text { data we concluded that it was uploaded by someone born in 1979. } \\
\text { Under the pressure of global management, we had to dismiss four } \\
\text { workers from our factory without any evidence whatsoever." }\end{array}$ \\
\hline $\begin{array}{l}\text { Trumped-up } \\
\text { disciplinary cases } \\
\text { and dismissals }\end{array}$ & $\begin{array}{l}\text { "All my efforts to 'keep' a colleague were in vain. Later his superior } \\
\text { confides to me that the person in question was put on the dismissal } \\
\text { list simply because he happened to find a 'bigger boss' in a rather } \\
\text { intimate situation with a female colleague." }\end{array}$ \\
\hline
\end{tabular}

Source: author

\subsection{Recruitment and selection}

28 cases were directly concerned with this issue. The main foci were the following:

Many cases relate to the recruitment and selection process with the inappropriate use of recruitment tools (i.e. assessment centre, stress interview, requiring references, monitoring of social media, the hiring of a private detective). No respect is given to the candidates' dignity or intellectual property. The doubt in the sincerity of feedback or the lack of it, and making false promises also appeared.

Although inherent in the process, discriminative cases must be given special attention. Although not part of the system (since the law ensures equal treatment to everyone), it is apparent in the attitude of leaders and HR experts, or perhaps it is encoded in organizational culture, such as the turning down of applicants over 50 (ageism), a young single woman or mother with a small child, the discrimination of disabled, physically injured, overweight, less attractive, or even unfriendly applicants. There is also the ethical aspect of the preference for the employment of disabled candidates because of financial or tax incentives. 
A special segment of dilemmas involves the employing of certain candidates as dictated from higher levels or from abroad. Another common dilemma is related to employing relatives or acquaintances. Such issues mean a constant struggle for HR professionals, especially in smaller cities and closed commuities.

Cases of abusing vulnerable candidates also occur, with the HR manager taking advantage, for example, when being unemployed, elderly or a trainee affects the wage bargain, or the person is employed only for a probation period.

Another characteristic group is cases of information retention (or in specific cases the falsification of facts). The organization puts a candidate in a disadvantaged position due to the retention of information, e.g. about forthcoming negative organizational change. Candidates on the other hand also retained or overstated relevant data (e.g. overstating previous work experience).

Table 4. Patterns related to recruitment with characteristic cases

\begin{tabular}{|c|c|}
\hline Foci & Characteristic case or excerpt from a case \\
\hline Selection process & $\begin{array}{l}\text { "We carried out a multiple-round interview to fill a position. In the sec- } \\
\text { ond round, candidates had to make a presentation for the launching of a } \\
\text { new product including competitors, marketing solutions, etc. With the } \\
\text { consent of the candidates, the company saved each presentation to col- } \\
\text { lect as many ideas as possible for its own use." }\end{array}$ \\
\hline Discrimination & $\begin{array}{l}\text { "One of our HR partners, maybe he became one too soon, very young, } \\
\text { first job and full of prejudices. He will not call in an applicant because } \\
\text { he doesn't like the photo on the CV or because he thinks the applicant } \\
\text { is too old/young, has too much/too little experience or looks too good/ } \\
\text { too bad ('Why would this one need a job when he/she could make a } \\
\text { living otherwise?'). Or on another occasion, he wouldn't call in the one } \\
\text { and only applicant for a position in a tucked away branch because there } \\
\text { were no other applicants and 'Anyway, what the hell is that so and so } \\
\text { college'?" }\end{array}$ \\
\hline $\begin{array}{l}\text { Handling of 'protégé' } \\
\text { candidates }\end{array}$ & $\begin{array}{l}\text { "At present, I'm working as an HR leader for a service company which } \\
\text { is a } 100 \% \text { affiliate of a larger corporation. Quite often we receive calls } \\
\text { from senior managers at the parent company saying that a spouse or an } \\
\text { acquaintance is looking for a job and (with an emphatic tone) it would } \\
\text { be nice to find something for them." }\end{array}$ \\
\hline $\begin{array}{l}\text { Abuse of vulnerable } \\
\text { candidates }\end{array}$ & $\begin{array}{l}\text { "There are two vacancies. The first candidate wants more money. We } \\
\text { raise his pay and make a new offer although he was younger and had } \\
\text { less experience. And then comes this other colleague [...]. We knew she } \\
\text { wouldn't ask for that much and lower pay would just suffice because } \\
\text { she was in a difficult situation as she had to leave her previous company } \\
\text { and had small children." }\end{array}$ \\
\hline Information retention & $\begin{array}{l}\text { "An employee in a very important senior position announces she is } \\
\text { pregnant at the end of the probation period." }\end{array}$ \\
\hline
\end{tabular}

Source: author 


\subsection{Organizational culture}

This issue involved 22 cases with the following foci:

Cases related to the behavioural patterns of leaders, employees or subcultures e.g. humiliation, verbal aggression, intimidation, deception and manipulation at the workplace. The key issue here is how to detect these cases and what the role and responsibility of HRM is. A separate group is constituted by the cases of sexual harassment at the workplace. Detection, handling and sanctioning of those issued appeared in a number of cases.

Some cases involve the handling and regulation of short and long-term love affairs at the workplace. Different ethical dilemmas are raised by affairs between leader and leader (contrariety) or leader and employee (power asymmetry). Several companies (especially multinationals) have worked out regulations for these situations. However, more often than not, they are removed from real life and hard to apply.

Ethical dilemmas may be caused when an organization has to adopt and apply behavioural codes, regulations, and programs that are alien to its culture and were made by a parent company or external consultants.

In the last group, we deal with individuals or groups turning down, labeling or discriminating against minorities (e.g. females or disabled people). This, obviously, is related to discriminative practices that appear in recruitment and selection.

Table 5. Patterns related to organisational culture with characteristic cases

\begin{tabular}{|c|c|}
\hline Foci & Characteristic case or excerpt \\
\hline $\begin{array}{l}\text { Unethical behavioural } \\
\text { patterns }\end{array}$ & $\begin{array}{l}\text { "A number one leader in one of the areas I support gets an anonymu- } \\
\text { ous e-mail from an employee who names and accuses her boss of } \\
\text { sexual harassment, humiliation and intimidation. She threatens that } \\
\text { she will leak it to the media if we don't take necessary steps. The } \\
\text { e-mail is attached with a voice recording in which her superior sets } \\
\text { his colleagues to work rather harshly (not in a tone or manner one } \\
\text { would expect from a leader). She is available for a meeting in person } \\
\text { where she gives a detailed account of the atrocities she suffered. The } \\
\text { accused leader denies all charges. He says that in the past } 14 \text { years } \\
\text { he's been working with us he has always respected rules and regula- } \\
\text { tions." }\end{array}$ \\
\hline Love affairs & $\begin{array}{l}\text { "The HR boss went out and stayed together for a longer time with } \\
\text { one of the HR business partners. When this HR business partner took } \\
\text { part in our HR meetings she said she had an extra status in relation } \\
\text { to the HR boss which stirred up resentment in the other HR business } \\
\text { partners and HR colleagues." }\end{array}$ \\
\hline
\end{tabular}


Table 5. continued

\begin{tabular}{l|l}
\hline Foci & \multicolumn{1}{c}{ Characteristic case or excerpt } \\
\hline $\begin{array}{l}\text { Adoption regulations set } \\
\text { by the parent company }\end{array}$ & $\begin{array}{l}\text { "After the change in the owners, we had to implement the parent } \\
\text { company's Code of Behaviour in Hungary as well. At that time our } \\
\text { organizational culture was totally different. The Code was extremely } \\
\text { long and, in many parts, rather confusing. So, with a load of questions } \\
\text { and doubts still unsolved, HR had to make employees accept it." }\end{array}$ \\
\hline $\begin{array}{l}\text { Rejection of diversity } \\
\text { and discrimination }\end{array}$ & $\begin{array}{l}\text { "In certain departments leaders have qualms about people with dis- } \\
\text { abilities and - if possible - try to make them work from home, only } \\
\text { to get them out of sight. Some leaders say disabled employees are a } \\
\text { necessary evil and their performance doesn't even compare to that of } \\
\text { their able-bodied colleagues. As much as possible, personal meetings } \\
\text { are avoided. Making people work together against their will raises } \\
\text { another ethical question." }\end{array}$ \\
\hline
\end{tabular}

Source: author

\section{PATTERNS OF ETHICAL CASES - SUMMARY}

From certain aspects, the patterns experienced by participants show significant similarities to those revealed in the literature (see Table 1). Clearly, the most common issue is dismissal and disciplinary cases, which is probably partly due to the economic crisis of 2009-2010 and the consequent downsizing trends. The second issue is - similar to the literature - related to recruitment and selection. Favouritism (mainly in recruitment and compensation) and the emphatic appearance of discrimination bear a resemblance to the research findings of Ryan (2006) in Poland. This is confirmed by research findings on specific national cultures, which suggests that ties among relations, friends and acquaintances have a great importance in Hungary (Heidrich - Chandler 2015). We found that dilemmas concerning aggression, harassment and the handling of relationships at work are much more emphatic while work safety or data processing are of less importance. On the other hand, some issues mentioned in literature are totally absent, e.g. the representation of employee interests, (perhaps because in Hungary trade unions membership is waning), issues of work systems or drug abuse, which are mostly replaced by drinking problems, especially outside of the capital or at production firms.

One of the great learning points from these patterns is that in a high number of organizations, HRM processes (e.g. dismissal, recruitment, compensation, disciplinary cases) are non-transparent, non-definitive or decision-making is not consequential. It does not necessarily mean that there are no regulations about processes, but that they are not detailed enough or do not cover real-life situations (because they are outdated or have always been alien to practice) or perhaps not applicable to 'everybody'. Ethical dilemmas often focus on the behaviour or conduct of top leaders but, surprisingly, HR managers themselves also have a number of ethical 
problems with handling processes, their own role, their own decisions or their own passivity (Ekuma - Akobo 2015). Several times they encountered the issues of to what extent and how long they are responsible for the problems and defects with selection or disciplinary processes and what they do to find a solution.

On the basis of the evidence provided by these cases, we must face the fact that even large multinationals are affected by illegal practices (or the intention thereof), e.g. forging time sheets or overtime data, 'grey' wage deals or tax manipulation. As Ryan (2006: 278) emphasized, "old habits die hard" - the habit of 'bending the rules' seems to be present. These cases often show that 'loyalty to the organization' or 'economic pressure' are used as legitimizing arguments. This attitude is very much in line with the mainstream utilitarian logic (Greenwood 2013) that the missing of a profitable business opportunity may cause more material loss to the organization than the gain to be had from respecting moral considerations.

A recurring motif was whether high-performance, 'valuable' employees should be treated differently, i.e. should we turn a blind eye to their ethical offenses or not? This, in a broader sense, raises the question of whether business success can legitimize unethical practices (Legge 1995). No definite answer was found during our talks, neither on a theoretical level, nor in real-life situations.

The issue of discrimination often appeared in recruitment processes in spite of the fact that in Hungary (and all EU countries) it is illegal to discriminate against people on grounds of gender, religion or health condition. Mothers with small children had the most marked representation among disadvantaged groups; their reintegration raises a high number of questions. The groups of old and disabled employees had also surfaced in this context - these groups have even less power of representation than young mothers, as just to get admission to an organization often presents a problem for them, called 'access discrimination'.

Finally, participants perceived that in many organizations there are basic problems with sincere communication, the lack of trust, especially between management and employees or between HRM and employees. In a significant number of cases, HR managers may choose whether to speak out or not when they see unethical things. If they do speak out, they may face personal conflict, new grounds for attacks and extra work. Discourse on ethical issues is especially problematic as we shall see in the following sections.

\section{PATTERNS OF MORAL MUTENESS}

Moral muteness is present: a great majority of experts agreed that ethical arguments or an open discourse on ethicality is non-existent or very rare in organizational or HRM practice. "When I think back on the time I've been in business 
(12 years) I don't remember a single case when the term 'ethical' has ever come up in everyday routine. Since I've been socialized in this vein I've never felt the need to focus much on ethical things either - not even when I got into an HR position..." This attitude is not necessarily due to an intentional organizational directive, but rather to a generally accepted practice or taboo, rooted, perhaps, in a broader social context. "During our talks, it became clear to me that we usually treat ethical issues as a kind of taboo, in a rather 'immature' way. We have an ethical code which, unfortunately, we did not compile together. It contains basic principles whose real sense and meaning we have never discussed and we do have 'cases' about which we keep very quiet [...] I think we also have our distressing issues that should be settled but somehow we cannot or dare not talk about them openly."

Participants identified several (in certain cases directly correlated) reasons for muteness. One obvious factor might be the lack of ethical knowledge which has its roots in the educational system as well: "I'm not happy with the way ethics is taught at school. Our educational system gives too few examples of ethical behaviour to follow." Several participants indicated that they had never met ethical theories or issues during their school years or even now, at work, they seldom get impulses of this kind (either in the form of getting information, training programs or opportunities to raise questions). This gap could be a serious obstacle: as Ekuma and Akobo (2015) suggest, the awareness of ethical framwork could help engagement with ethical issues.

Even if ethical codes do exist - especially at large corporations - ethical training courses remain mere formalities to be ticked off quickly. In certain cases, courses are given to only a specific segment of employees (e.g. only white-collar workers). Although in many large companies there are ethical institutions or frameworks, they seldom function properly (i.e. there are no cases in the ethical hotline) and they provide neither inspiration nor space for the open discussion of ethical issues. Many HRM professionals confirmed that: "Large corporations all have their own ethical codes but these are mostly ignored. Neither management nor the employees identify with them and often don't even know they exist. If you accept that the more developed or advanced an organization or a professional area is, the more attention is given to ethical issues, it comes as a revelation that ethicality is merely a 'bubble' or may be - as even in my own organization - at the bottom of the list. Surely, everyone is much more familiar with company car or cafeteria regulations than with any paragraph in the ethical code." Several research studies suggest that the practice of large multinationals has a great impact on the practice of other companies, so this percieved 'non-functioning' of the ethical institutions could have a huge impact on the corporate practice. 
The phenomenon of 'non-use' or the sense of alienation may also be due to ignorance and fear. As a characteristic pattern, we must mention the practice when multinationals impose their own institutional framework on affiliated companies (in this case in Hungary) completely ignoring local employees in the setting up, adaptation or interpretation of regulations. "Yes, we have an ethical code at our company which every new employee accepts as compulsory, but we do not have a really well-functioning system for the detection and sanctioning of ethical offenses. The Ethical Hotline program has never been used in Hungary which, of course, doesn't mean that we are absolutely free from ethical problems. People are simply afraid or don't know how to use it or just don't care."

In certain companies exposed values and followed practices go completely separate ways (maybe 'exposed values' have never been genuine) and practices that go contrary to the ethical code become everyday routine: "Once upon a time there was an excellent company with a great set of values but behind the scenes it was all about intrigue, cheating and deception. Individual interests overrode the interests of the community so a kind of 'undercover' negative transformation eventually undermined corporate decision-making altogether." The role of HRM as ethical agents (Greenwood 2013) or developers of ethical culture (Verhezen 2010) suggested by the literature remains disputable. The words of an HRM professional, who got his experiences in a categorically unethical organizational culture, is rather alarming: "Chained-down dogs - that's what we are! The master sometimes rewards us with a little stroke - especially when we have made employees swallow another wage reduction." This is another addition to weighing the serious emotional effects caused by ethical dilemmas (Linehan - O'Brien 2017).

The implementation of ethical principles may be contrary to the power logic of the organization and even the use of sincere and open communication may be absent in organizational culture. In certain cases, the management is afraid that their own power may be damaged - at least the HRM professionals perceive it so. Also, sincerity may lead to conflict. "It's quite easy to say that we communicate sincerely and openly with one-another, the leaders or the employees (not to mention external clients) but, perhaps, this is exactly where most of the sensitive questions arise. Leaders 'play games' to fight for their own interests, to get more funds for a project, or to show a better image of themselves to the number one leader. They don't tell 'everything' to the employees so as to protect company interest or even because it may be 'unpleasant' or create a source of conflict." If the company is morally mute, HRM may also feel that they have no other option than to hide their own opinion as well, no matter what tension it causes them on the inside: "It's for two years now that I've been learning how to say 'other things' and in a different way than I would if I were a private person or if I wasn't at work 
[...]. I don't train myself to become a liar but a clever, diplomatic communicator in an organization. Between, above, under, in front of, behind management and employees. In all directions! And what shall I do with myself? With whom can I share my own feelings, questions or doubts? Who can I talk to openly without the 'clever gloss' all over my words?" In some cases, the HRM managers speak about emotional tensions and struggles (Linehan - O’Brien 2017) in connection with ethical dilemmas.

The fact that an HRM manager does not speak out may also be due to a loyalty to the organization or a wish to avoid (real or imagined) conflicts: "Another strong point in us is the commitment and loyalty to the company and a respect for senior management. But this drifts us into situations where we need to 'defend' their reputation, which, in turn, makes us do, or rather, not do things that go close or even go over our own ethical limits. [...] Sometimes we are just forced to 'do the job'."

In the interpretation of the participants, 'ethicality' often brings up negative emotional connotations. "When I come to think of it, well, this topic is generally ignored at my workplace. Mostly negative emotions are linked to it. Even the term 'ethical' brings up things like 'ethical offense' or 'ethical committee'." Indeed, many people do not associate ethics with having proper conduct, the representation of values like justice or fairness. Instead, they think of negative experiences, e.g. ethical offence, negligence or sanctions. "What comes to my mind is shutting-up, fear, threats, insecurity, intimidation [...]. Also, even the language of regulations is much more concerned with potential negligence and offenses. Especially in legal cases, it's not so much about trying to reach a professionally justifiable or reasonable compromise as about the manipulations of a 'hurt' leader who abuses his power to take revenge for his 'sufferings'." Another important aspect here would be to make sure that employees keep to ethical norms not because they fear sanctions, but because of some moral values or considerations.

The discourse on moral muteness also includes references to buck-passing, and going with the flow: "I think it quite probable that bigger and bigger abuse committed at the firm began with small steps. I don't think anyone would start a new job with the intention of breaking laws, by all means, or to trample on other people to secure fictitious interests. Many of them are not even aware what their actions may cause to others and they are even convinced they do the best possible thing. 'We are only doing our job. You cannot blame us for it!' [...] So, if I don't take part in their dirty little tricks and businesses then I do not qualify for membership in 'the club' and cannot expect any support or sympathy for my own initiatives [...]."

Finally, in the interpretation of the participants, moral muteness may also be related to our broader social and economic environment. "In today's Hungary 
ethical issues are influenced considerably by moral and legal conditions as well. Well, if I want to be very honest with myself, here in Hungary it's quite hard to avoid 'bending the rules' or 'covering things up' instead of speaking out when you see something wrong. But it seems to me we just want to find excuses. We can always say: why should I do it differently? Why shouldn't I sign that contract as it is and that's that! Everybody does the same." The themes of 'everybody does the same' or 'nobody acts ethically' appear in a broader context as well.

The themes or moral muteness are summed up in Table 6 .

Table 6. Reasons for moral muteness as identified by the literature and patterns found in the research

\begin{tabular}{l|c}
\hline Occurrence pattern & Issues identified by the literature \\
\hline $\begin{array}{l}\text { Knowledge of ethical conduct is scarce, no proper impar- } \\
\text { tation of knowledge even within the organization }\end{array}$ & Fear of losing power \\
\hline $\begin{array}{l}\text { The ethical institutional framework is "ead' or non- } \\
\text { relevant }\end{array}$ & Fear of losing power \\
\hline $\begin{array}{l}\text { Codes, frameworks and regulations are too formal, far } \\
\text { removed from everyday practice and in some cases 'dead" }\end{array}$ & Fear of losing power \\
$\begin{array}{l}\text { The concept of ethicality is associated with fear, negative } \\
\text { emotions and discouraging experiences }\end{array}$ & Fear of losing power \\
\hline $\begin{array}{l}\text { HRM professionals are loyal and do not want to get into } \\
\text { conflict with leaders }\end{array}$ & $\begin{array}{c}\text { Fear of losing harmony, } \\
\text { loyalty to the organization }\end{array}$ \\
\hline $\begin{array}{l}\text { Leaders do not want damage to their power games so } \\
\text { they are not sincere }\end{array}$ & $\begin{array}{c}\text { Fear of losing harmony, } \\
\text { loyalty to the organization }\end{array}$ \\
\hline "We are only doing our job" & Passing responsibility \\
\hline The role of the socio-economic context & Cynicism \\
\hline
\end{tabular}

Source: author

\section{CONCLUSION}

In this paper, we presented the most common ethical dilemma patterns mentioned by Hungarian HRM professionals and showed their interpretations of moral muteness. Based on the findings, we share three concluding thoughts, refer to the limitations of our study and offer some future research directions.

First, while HRM ethics is a fascinating and emerging theoretical field of study, ethical dilemmas themselves are not abstract issues, but serious problems frequently present in daily practice, affecting HRM professionals, employees and managers. So labelling ethics as a purely theoretical issue, 'alien' from practice is only true in a sense that discussing ethical issues is indeed 'alien' from the daily practice. The most important conclusion of the paper is that closing our eyes, ignoring these problems or refusing our responsibilities does not mean they do not 
exist. On the contrary, open, honest and brave dialogue about ethically questionable issues and situations could not only facilitate more ethical solutions of actual problems, but could also help to build more honest and transparent corporate cultures.

Second, one of the recurring patterns was that HRM professionals had serious doubts about their behavior in certain situations (e.g. 'I should have handled that dismissal differently...', 'I should have stood up at that moment...'), but they lacked the knowledge to build on, were not sure about their responsibility or were not thinking it over. This insecurity (sometimes even passivity) on the individual (micro) level could cause serious system-level problems at the corporate level, like a lack of transparency or discriminative practices, as found in several cases. Personal doubts and ethically problematic HR systems are embedded in the socio-economic context (macro), clearly reflecting the interconnectedness of those levels. So again, studying the phenomenon would mean studying all three levels at the same time.

Third, several professionals confessed that it was important for them to realize that they are not alone: "In countless cases, I realized with astonishment that even though we may come from quite different areas and have different positions in HR hierarchy, we have very similar problems and dilemmas." The above notion definitely confirmed the significance of the role the professional community can play in ethical discourse. A number of participants also revealed that apart from the positive conclusions they gained, their ideas about 'good practice' had also been challenged and this may influence their decision-making in the future. "I also got answers to my latent, subconscious questions and I must admit they upset me quite a bit. Not because I couldn't agree but it felt a bit like looking through a situation with all its beauty and difficulties blended together. So I suddenly found myself remembering situations when the decisions that had been made earlier would not necessarily be acceptable for me today." Again, open dialogue and supporting communicative space could be a starting point for positive change.

The findings are bounded by the study's limitations. First of all, the findings reflect the researcher's individual perceptions of what is important and relevant. Second, the 76 HRM professionals participated do not represent in any sense the whole professional community in Hungary, so the patterns found could not be considered as a generally valid picture. The HRM ethics class and the 5 groups, as a context for data collection, and the author, as an academic instructor together with her experiences and expectations, could also have had an impact on the cases shared. Furthermore, the 5 years of data collection period is also a limitation, because the external environment changed significantly during this period (for example the migration crisis, workforce shortage, Brexit, etc.), which surely had 
an impact on the research. Besides those limitations, the intention was to explore and show some patterns and insights which could deepen our understanding of ethical dilemmas.

We believe that there are many, both interesting and relevant research directions. First of all, effected HR systems (e.g. recruitment) and problems identified (e.g. favorism) should be analysed more deeply, paying attention to their dynamics, their corporate and social-economic context, and including the voices of other corporate stakeholders (employees, managers), showing possible coping strategies. Second, the study of (non-) functioning of ethical institutions and their connections to the HR function seems to be a relevant field. Third, the (possible) moral muteness of top managers, especially in Central-Europe, could be an interesting, yet under-reseached area. Finally, further investigation about ethical views of HRM professionals and the ethical standards of the HRM profession could be an interesting field for development.

\section{REFERENCES}

Bird, F. B. (2005): Moral Muteness. In: Werhane, P. H. - Freeman, R. E. (eds): The Blackwell Encyclopedia of Management. Business Ethics. Oxford: Blackwell Publishing, pp. 360-363.

Bird, F. B. - Waters, J. A. (1995): The Moral Muteness of Managers. In: Stackhouse, M. L. (ed.): On Moral Business. Eerdmans Publishing Company, pp. 888-897.

Bolton, S. - Houlihan, M. (2007): Searching for the Human in HRM. London: Palgrave Macmillan.

Brinkmann, J. - Lindeman, B. - Sims, R. (2016): Voicing Moral Concerns: Yes, but How? The Use of Socratic Dialogue Methodology. Journal of Business Ethics 139(3): 619-631.

Csillag, S. (2013): Walking a Thin Line? Action Learning Research and Practice 10(2): 124-147.

Dachler, H. P. - Enderle, G. (1989): Epistemological and Ethical Considerations in Conceptualizing and Implementing Human Resource Management. Journal of Business Ethics 8(8): 597-606.

De Cieri, H. - Kramar, R. (2005): HRM in Australia. North Ryde: McGraw Hill.

Deckop, J. - Giacalone, R. - Jurkiewicz, C. L. (2006): HRM ethics. Greenwich: Information Age.

De Cremer, D. (2009): Psychological Perspectives on Ethical Behavior and Decision Making. Charlotte: Information Age Publishing.

Drumwright, M. - Murphy, P. (2004): How Advertising Practitioners View Ethics: Moral Muteness, Moral Myopia, and Moral Imagination. Journal of Advertising 33(2): 7-24.

Ekuma, K. J. - Akobo, L. A. (2015): HRM Ethics and Professionals' Dilemmas: A Review and Research Agenda. Human Resource Management Research 5(3): 47-57.

Fusilier, M. R. - Aby, C. D. - Worley, J. K. - Elliott, S. (1996): Perceived Seriousness of Business Ethics Issues. Business \& Professional Ethics Journal 15(1): 67-78.

Goodpaster, K. (2007): Conscience and Corporate Culture. Blackwell: Oxford.

Greenwood, M. R. (2013): Ethical Analyses of HRM: A Review and Research Agenda. Journal of Business Ethics 114(2): 355-366.

Guerci, M. (2015): The Impact of HRM Practices and Corporate Sustainability on Organizational Ethical Climates. Journal of Business Ethics 126(2): 325-342. 
Heidrich, B. - Chandler, N. (2015): Four Seasons in One Day: The Different Shades of Organisational Culture in Higher Education. Management Dynamics in the Knowledge Economy 3(4): $559-588$.

Jacobs, G. - Belschak, F. - Hartog, D. (2014): (Un)Ethical Behavior and Performance Appraisal: The Role of Affect, Support, and Organizational Justice. Journal of Business Ethics 121(1): 63-76.

Legge, K. (1995): Human Resource Management: Rhetorics and Reality. London: Macmillan.

Linehan, C. - O'Brien, E. (2017): From Tell-Tale Signs to Irreconcilable Struggles: The Value of Emotion in Exploring the Ethical Dilemmas of HR Professionals. Journal of Business Ethics 141(4): 763-777.

Longenecker, C. - Ludwig, D. (1990): Ethical Dilemmas in Performance Appraisal Revisited. Journal of Business Ethics 9(12): 961-969.

Lowell, A. (2003): The Enduring Phenomenon of Moral Muteness. Suppressed Whistleblowing. Public Integrity 5(3): 187-204.

Martin, G. - Woldring, K. (2001): Ready for the Mantle? Australian HR Managers as Stewards of Ethics. International Journal of Human Resource Management 12(2): 243-255.

Mathis, R. - Jackson, J. (1997): Human Resource Management. USA: Thompson.

McCoy, B. (1989): The Parable of a Sadhu. In: Andrews, K. (ed): Ethics in Practice. Boston: Harvard Business School Press, pp. 201-207.

Nasir, S. (2015): Emerging Challenges of HRM in 21st Century. International Journal of Academic Research in Business 7(3): 216-223.

Orlitzky, M. - Swanson, D. (2006): Socially Responsible HRM. In: Deckop, J. (ed.): Human Resource Management Ethics. Greenwich, Connecticut: Information Age Publishing, pp. 3-24.

Park, K. M. - Hollinshead, G. (2011): Logics and Limits in Ethical Outsourcing and Offshoring in the Global Financial Services Industry. Competition \& Change 15(3): 177-195.

Pichler, S. - Varma, A. - Michael, J. S. - Levy, P. E. (2016): Leader-Member Exchange, Group- and Individual-Level Procedural Justice and Reactions to Performance Appraisals. Human Resource Management 55(5): 871-883.

Pinnington, A. - Macklin, R. - Campbell, T. (2007): HRM Ethics and Employment. Oxford: Oxford University Press.

Ryan, L. V. (2006): Current Ethical Issues in Polish HRM. Journal of Business Ethics 66(2-3): 273-290.

Schumann, P. (2001): A Moral Principles Framework for Human Resource Management Ethics. Human Resource Management Review 11(1-2): 93-111.

Sung, S. Y. - Choi, J. N. - Kang, S. C. (2017): Incentive Pay and Firm Performance: Moderating Roles of Procedural Justice Climate and Environmental Turbulence. Human Resource Management 56(2): 287-305.

Verhezen, P. (2010): Giving Voice in a Culture of Silence. Journal of Business Ethics 96(2): 187206.

Waters, J. - Bird, F. - Chant, P. (1986): Everyday Moral Issues Experienced by Managers. Journal of Business Ethics 5(5): 373-384.

Weiss, W. H. (1997): The Need for Ethical Behavior. Supervision 58: 15-18.

Wiley, C. (1998): Reexaminating Perceived Ethics Issues and Ethics Roles among Employment Managers. Journal of Business Ethics 17(2): 147-161.

Winstanley, D. - Woodall, J. (2000): The Ethical Dimensions of HRM. Human Resource Management Journal 10(2): 5-20. 